\title{
BLUNT IMPACT TO THE CHEST LEADING TO SUDDEN DEATH FROM GARDIAC ARREST DURING SPORTS ACTIVITIES
}

\author{
Barry J. Maron, M.D., Liviu C. Poliac, M.D., James A. Kaplan, M.D., and Frederick O. Mueller, Ph.D.
}

\begin{abstract}
Background. Sudden death from cardiac arrest in a young person may occur during sports play after a blunt blow to the chest in the absence of structural cardiovascular disease or traumatic injury (cardiac concussion or commotio cordis). We studied the clinical features of this apparently uncommon but important phenomenon.

Methods. We identified cases from the registries of relevant agencies and organizations, as well as newsmedia accounts, and developed a clinical profile of 25 children and young adults, 3 to 19 years of age.

Results. Each victim collapsed with cardiac arrest immediately after an unexpected blow to the chest, which was usually inflicted by a projectile (such as a baseball or hockey puck). Incidents took place during organized competitive sports in 16 cases and in recreational settings at home, at school, or on the playground in 9. In each instance, the impact to the chest was not judged to be extraordinary for the sport involved and did not appear to
\end{abstract}

$\mathrm{S}$ UDDEN death in a young athlete is a dramatic event that has attracted considerable attention. ${ }^{1}$ Most such catastrophes have been shown to be the consequence of unsuspected congenital or acquired cardiovascular disease..$^{2-12}$ However, we attempted to expand our understanding of sports-related sudden deaths by focusing on a less well recognized cardiac-related cause of death in young healthy people. ${ }^{13-15}$ We describe the clinical profiles of a series of young sports participants in whom blunt, nonpenetrating blows to the chest, apparently insufficient to produce structural injury, resulted in cardiac arrest and sudden death.

\section{Methods}

The catastrophic events included in the present study were identified through reviews of the registries and available records of the U.S. Consumer Product Safety Commission (Washington, D.C.), the National Center for Catastrophic Sports Injury Research (Chapel Hill, N.G.), and Little League Baseball (Williamsport, Pa.), as well as from accounts in the news media. To be included, an event had to satisfy the following conditions: it had to involve a blunt, nonpenetrating impact to the precordial area immediately preceding the collapse; it had to have occurred during an organized competition or game or while the victim was practicing or playing a sport; there had to be no structural damage to the sternum, ribs, or heart; and detailed documentation of the incident had to be available from autopsy and police reports, newspaper articles, and telephone interviews with witnesses and family members. Of the 25 incidents included in the study, 20 occurred between 1986 and 1995 and 5 between 1977 and 1983; 4 of the 25 incidents have been described previously. ${ }^{16-18}$

\section{Results}

\section{Demographic Characteristics}

The ages of the 25 victims ranged from 3 to 19 years (with a mean of 11); 18 of them were under 16 years

From the Cardiovascular Research Division, Minneapolis Heart Institute Foundation, Minneapolis (B.J.M., L.C.P.); the Office of the New Hampshire State Medical Examiner and the Department of Pathology, Dartmouth Medical School, both in Lebanon, N.H. (J.A.K.); and the National Center for Catastrophic Sports Injury Research and the University of North Carolina, both in Chapel Hill (F.O.M.). Address reprint requests to Dr. Maron at the Minneapolis Heart Institute Foundation, 920 E. 28th St., Suite 40, Minneapolis, MN 55407-3984. have sufficient force to cause death. Twelve victims collapsed virtually instantaneously on impact, whereas 13 remained conscious and physically active for a brief time before cardiac arrest. Cardiopulmonary resuscitation was administered within about three minutes to 19 victims, but normal cardiac rhythm could be restored in only 2 (both incurred irreversible brain damage and died shortly thereafter). Seven victims (28 percent) were wearing some form of protective chest padding.

Conclusions. We speculate that most sudden deaths related to impact to the chest (not associated with traumatic injury) are due to ventricular dysrhythmia induced by an abrupt, blunt precordial blow, presumably delivered at an electrically vulnerable phase of ventricular excitability. This profile of blunt chest impact leading to cardiac arrest adds to our understanding of the range of causes of sudden death on the athletic field and may help in the development of preventive measures. (N Engl J Med 1995;333:337-42.)

old. Twenty-four subjects were male and 1 was female; 22 were white and 3 were black. The deaths occurred during participation in a variety of sports but were most common in baseball or softball $(n=18)$ (Fig. 1 and Table 1). Of the 25 victims, 16 were participating in organized competitive sports (during a game in 8 cases or during practice for competition in 8 others); 5 were high-school students, 1 was in college, 1 was a professional athlete, and 9 were participating in youth sports, including Little League baseball. The remaining nine subjects were not considered to be competitive athletes, and their deaths occurred during recreational sports activities at home, at a playground or park, or at school.

\section{Characterization of the Impact to the Chest}

\section{Competitive Sports}

In each of 12 of the 16 victims who were engaged in interscholastic or community-organized competition, localized impact to the precordium was caused by a blunt projectile propelled against the stationary chest wall; the projectiles were most commonly baseballs $(n=9)$, but also included hockey pucks in two cases and a lacrosse ball in one. The other four athletes each received a blow to the chest with broader surface contact, from a football helmet during a tackle, the heel of a hockey stick, a karate kick, or an opponent's shoulder (i.e., a body check during a hockey game) (Table 1).

Nine of these 16 competitive athletes were participating in organized baseball. Six of the nine baseball players were batters - five were struck by a pitched ball and one by a ball ejected from a pitching machine. In each of these six incidents, the body size and athletic ability of the pitcher and the speed of the ball were not considered to be extraordinary (the speeds were estimated or measured to be 48 to $80 \mathrm{~km}$ per hour [30 to 50 miles per hour] at distances of 12 to $14 \mathrm{~m}$ [ 40 to 45 $\mathrm{ft}]$ ). The circumstances of the other three baseballrelated fatalities were somewhat different. In one, a 


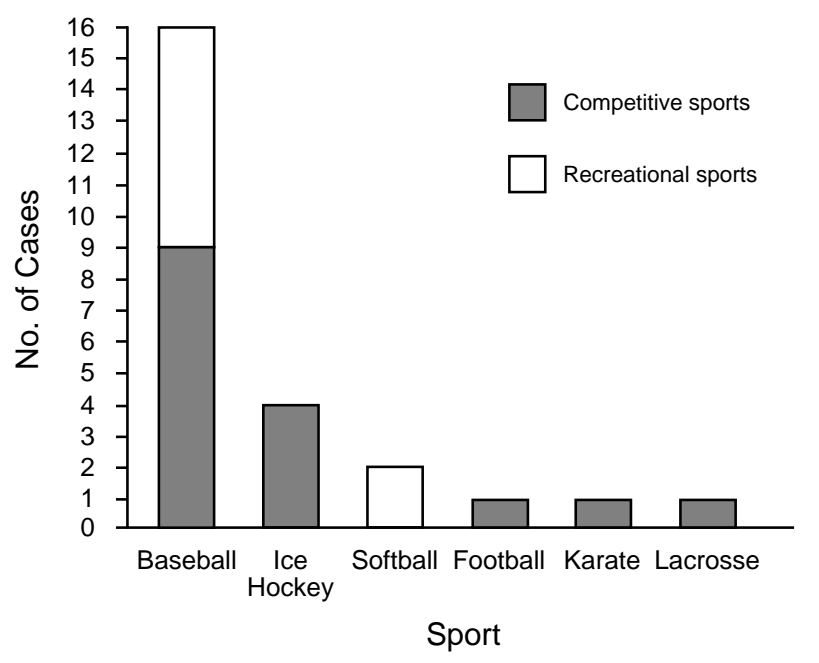

Figure 1. Participation in Competitive and Recreational Sports at the Time of Sudden Cardiac Death Induced by Blunt Impact to the Chest.

catcher was struck directly in the middle of the chest by an undeflected ball pitched at a distance of $18 \mathrm{~m}(60$ ft) (Subject 16, Table 1). In two other instances, a player in the field was struck in the chest by a ball (one,
Subject 19, by a hard-hit line drive traveling $30 \mathrm{~m}[100$ $\mathrm{ft}]$, and the other, Subject 24, by a ball thrown $37 \mathrm{~m}$ $[120 \mathrm{ft}])$.

\section{Recreational Sports}

Nine other deaths (of young people 3 to 16 years of age; mean, 6 years) occurred during play in informal settings either at home, at a playground or park, or in school; seven of these incidents involved baseballs and two involved softballs (Table 1). In each case, a ball struck a child in the chest at relatively close range after being batted or thrown either along the ground or in the air, in an arc or on a line. Bystanders judged that the speed of the ball on impact was not unusual. In each instance, the ball had been hit or thrown by a friend or relative of the victim (seven were parents or siblings).

\section{Circumstances of the Collapse}

After the blunt impact to the chest, 12 of the 25 victims collapsed to the ground virtually instantaneously, apparently in cardiac arrest. In the other 13, death was not instantaneous (Table 1). Some of these victims collapsed to the ground immediately on impact and others remained standing, but all of them then briefly performed some kind of conscious physical activity or

Table 1. Clinical Data on 25 Victims of Blunt Impact to the Chest Resulting in Sudden Cardiac Death.

\begin{tabular}{|c|c|c|c|c|c|c|c|}
\hline Subject No. & $\operatorname{AgE}(\mathrm{YR}) / \mathrm{SEX}$ & SPORT* & Circumstances of Impact to the Chest & Collapse $\dagger$ & $\begin{array}{l}\text { CPR IN } \\
\leqslant 3 \text { MIN } \ddagger\end{array}$ & $\begin{array}{c}\text { Chest } \\
\text { PADDING }\end{array}$ & $\begin{array}{c}\text { ChEST } \\
\text { Contusion } \$\end{array}$ \\
\hline 1 & $3 / \mathrm{M}$ & Baseball (R) & $\begin{array}{l}\text { Struck by ball batted off T-ball stand } 6-8 \mathrm{~m}(20-25 \mathrm{ft}) \text { away by } \\
6 \text {-year-old brother near home }\end{array}$ & A & Yes & No & Yes \\
\hline 2 & 3/M & Baseball (R) & $\begin{array}{l}\text { Struck by ball batted at close range }(5 \mathrm{~m}[15 \mathrm{ft}]) \text { by } 10 \text {-year-old } \\
\text { brother in front yard of home }\end{array}$ & I & Yes & No & No \\
\hline 3 & $4 / \mathrm{F}$ & Softball (R) & $\begin{array}{l}\text { Pitcher struck by ball batted at close range by } 9 \text {-year-old sister } \\
\text { in back yard of home }\end{array}$ & $\mathrm{I}$ & Yes & No & No \\
\hline 4 & $4 / \mathrm{M}$ & Baseball (R) & $\begin{array}{l}\text { Struck by ball batted by father along the ground }(30 \mathrm{~m}[100 \mathrm{ft}]) \\
\text { that suddenly bounced up; in back yard of home }\end{array}$ & A & Yes & No & Yes \\
\hline 5 & $5 / \mathrm{M}$ & Baseball (R) & Struck by line-drive hit by adult friend on playground & I & Yes & No & No \\
\hline 6 & $6 / \mathrm{M}$ & Baseball (R) & $\begin{array}{l}\text { Struck by ball thrown by mother ( } 26 \mathrm{~m}[85 \mathrm{ft}]) \text { in } 45 \text {-degree arc, } \\
\text { in back yard of home }\end{array}$ & A & Yes & No & Yes \\
\hline 7 & $7 / \mathrm{M}$ & Baseball (R) & $\begin{array}{l}\text { Struck by batted ball while standing } 5 \mathrm{~m} \text { behind and to the right } \\
\text { of batter, an } 8 \text {-year-old brother, in back yard of home }\end{array}$ & I & No & No & Yes \\
\hline 8 & $8 / \mathrm{M}$ & Baseball (C) & $\begin{array}{l}\text { Batter struck by ball pitched } 14 \mathrm{~m}(45 \mathrm{ft}) \text { by } 12 \text {-year-old during } \\
\text { batting practice }\end{array}$ & A & Yes & No & Yes \\
\hline 9 & $8 / \mathrm{M}$ & Baseball (C) & Batter struck by ball pitched $14 \mathrm{~m}$ by 9 -year-old during game & I & Yes & No & No \\
\hline 10 & 9/M & Baseball (C) & Batter hit by ball pitched $12 \mathrm{~m}(40 \mathrm{ft})$ during game & A & Yes $\rrbracket$ & No & No \\
\hline 11 & $9 / \mathrm{M}$ & Baseball (C) & Batter hit by ball pitched $12 \mathrm{~m}$ during game & A & Yes $\rrbracket$ & No & Yes \\
\hline 12 & $10 / \mathrm{M}$ & Baseball (C) & Batter struck by ball pitched $14 \mathrm{~m}$ by 9 -year-old during game & A & No & No & Yes \\
\hline 13 & $10 / \mathrm{M}$ & Baseball (R) & $\begin{array}{l}\text { Struck by batted line drive at } 12 \mathrm{~m} \text { while attempting to catch ball } \\
\text { during school recess }\end{array}$ & I & Yes & No & Yes \\
\hline 14 & $12 / \mathrm{M}$ & Baseball (C) & Batter hit by ball ejected by pitching machine at $14 \mathrm{~m}$ & I & Yes & No & Yes \\
\hline 15 & $14 / \mathrm{M}$ & Lacrosse (C) & Goalie hit by shot on goal at $14 \mathrm{~m}$ during practice & I & Yes & Yes & Yes \\
\hline 16 & $14 / \mathrm{M}$ & Baseball (C) & Catcher hit by pitched ball at $18 \mathrm{~m}(60 \mathrm{ft})$ during game & A & Yes & Yes & No \\
\hline 17 & $15 / \mathrm{M}$ & Hockey (C) & Struck by puck from a forehand shot at $6 \mathrm{~m}(20 \mathrm{ft})$ during game & A & Yes & Yes & Yes \\
\hline 18 & $15 / \mathrm{M}$ & Hockey (C) & Struck by puck from forehand slap shot at $9 \mathrm{~m}(30 \mathrm{ft})$ during game & I & Yes & Yes & Yes \\
\hline 19 & $16 / \mathrm{M}$ & Baseball (C) & Hit by batted line drive at $30 \mathrm{~m}$ during batting practice & I & Yes & No & No \\
\hline 20 & $16 / \mathrm{M}$ & Karate $(\mathrm{C})$ & Kicked sharply by opponent at close range during match & I & Yes & No & No \\
\hline 21 & $16 / \mathrm{M}$ & Softball (R) & $\begin{array}{l}\text { Struck by batted ball at } 27 \mathrm{~m}(90 \mathrm{ft}) \text { during family game in pub- } \\
\text { lic park }\end{array}$ & A & No & No & No \\
\hline 22 & $16 / \mathrm{M}$ & Hockey (C) & $\begin{array}{l}\text { Bodily collision with another player (i.e., body check) during } \\
\text { game - shoulder thrust into left chest area of victim }\end{array}$ & A & Yes & Yes & No \\
\hline 23 & $18 / \mathrm{M}$ & Football (C) & Struck by helmet while tackling ball carrier during game & A & No & Yes & No \\
\hline 24 & $18 / \mathrm{M}$ & Baseball (C) & $\begin{array}{l}\text { Struck near second base by ball thrown by catcher } 37 \mathrm{~m} \\
(120 \mathrm{ft}) \text { during pregame practice }\end{array}$ & A & No & No & No \\
\hline 25 & $19 / \mathrm{M}$ & Hockey (C) & Slashed with heel of hockey stick at close range during game & I & No & Yes & No \\
\hline
\end{tabular}

* $\mathrm{R}$ denotes recreational sport, and $\mathrm{C}$ competitive sport.

$\dagger$ A denotes a victim who demonstrated some activity after impact and before final collapse, and I, instantaneous collapse

$\doteqdot$ CPR denotes cardiopulmonary resuscitation.

§ yes indicates a contusion was present on the left precordium, probably representative of the site of impact.

IVictim was in a coma, with irreversible brain damage, four days (Subject 11) or nine days (Subject 10) before death. 
movement - opening their eyes, rising to a standing position (or attempting to do so), speaking or crying, vomiting, picking up and throwing a baseball, or walking or skating a few feet — before subsequently collapsing once again, apparently in cardiac arrest. None of these victims had cyanosis or respiratory distress shortly after the impact.

\section{Resuscitation}

In 19 of the 25 victims, efforts at cardiopulmonary resuscitation were initiated by bystanders or emergency medical technicians immediately or in a timely fashion (within about three minutes) (Table 1). Seven of these initial resuscitation attempts were carried out by trained personnel, including a registered nurse, a firefighter, physicians, and nonprofessionals trained in cardiopulmonary resuscitation. In each incident, licensed emergency medical technicians (either from mobile units or in the hospital emergency room) later became directly involved. In only two subjects (both nine-year-old baseball players, Subjects 10 and 11) was cardiac rhythm ultimately restored as a result of timely resuscitative efforts; however, each experienced irreversible brain damage and ultimately died in coma, nine and four days, respectively, after their initial collapse.

\section{Protective Padding}

Among the 25 study subjects, 18 (72 percent) were not wearing clothing that could be regarded as protective, and therefore their chests had been fully exposed to the impact. Seven other victims (28 percent), all competitive athletes, were wearing some type of standard, commercially available protective gear or padding, which appeared to cover the area of impact in the midchest. Four of these seven were playing hockey; of the other three, one was a football player, one was a lacrosse goalie, and one was a baseball catcher (Table 1).

In three deaths, the protective equipment worn commercially available gear designed to protect the chest - was known specifically to be composed of hard plastic with adherent foam-and-fabric covering (worn by Subject 17 to play hockey) or foam closed in fabric (worn by Subject 18 to play hockey and Subject 15 to play lacrosse). It was suggested in one of the hockeyrelated fatalities (Subject 17) that the chest padding may have moved up during play, allowing the puck to come into direct contact with the unprotected chest wall (Fig. 2).

\section{Autopsy Findings}

Complete autopsy examinations, employing standard procedures and techniques and including careful examination of the coronary arteries, were performed in 22 of the 25 victims by the medical examiners. Each of these 22 subjects was free of structural cardiovascular diseases known to cause sudden death in young people. ${ }^{1-12}$ Heart weights, wall thicknesses, and cavity dimensions were judged to be normal, and there was no evidence of active or healed myocarditis, myocardial infarction, congenital coronary anomalies, aortic rupture, or any traumatic injuries to the heart, coronary arteries, or great vessels that might have contributed to or caused death. Valvular heart disease was absent, although one 12-year-old boy who died while playing baseball (Subject 14) had incidental findings suggestive of a floppy mitral valve.

In 12 victims, small contusions on the surface of the left side of the chest were judged to be the consequence of the blunt impact (Table 1 and Fig. 3). These lesions were oval or circular abrasions or bruises, 0.6 to $5.0 \mathrm{~cm}$ in diameter, and were located in the mid-precordium,

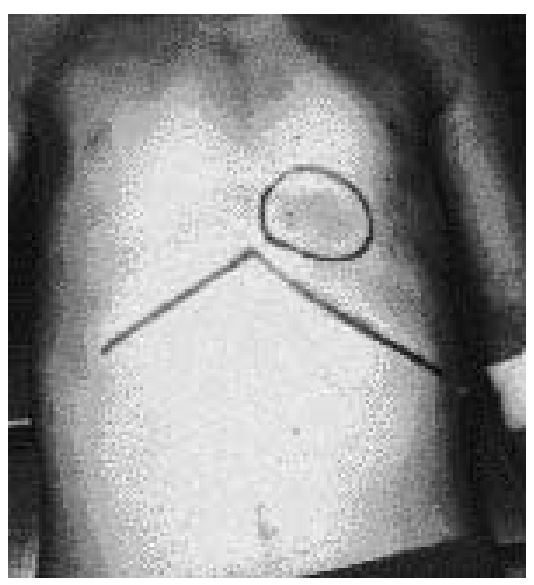

A

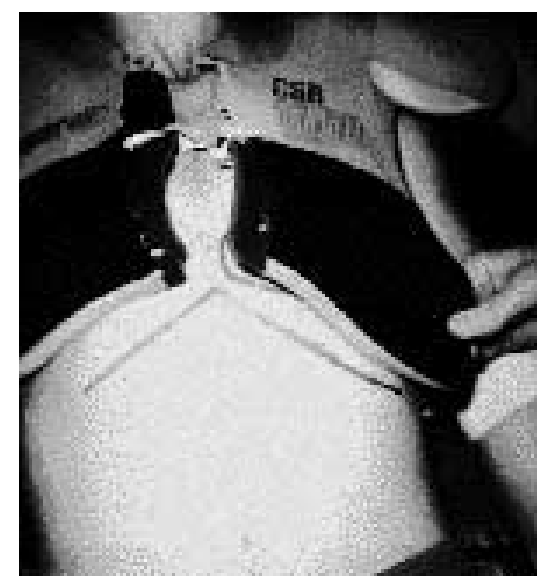

B

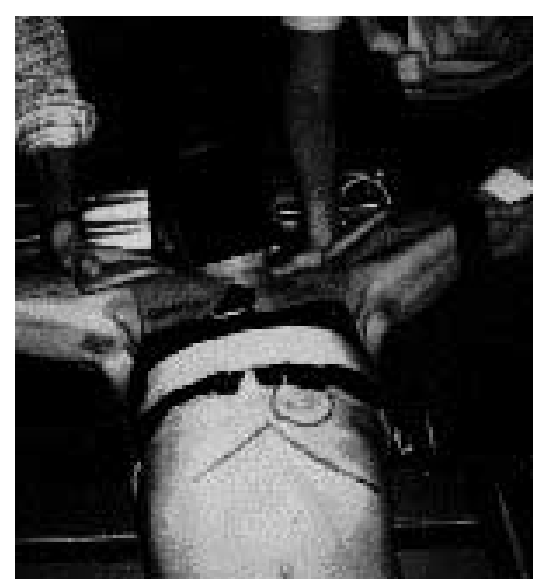

C

Figure 2. A 15-Year-Old Victim of Blunt Nonpenetrating Impact to the Chest Delivered by a Hockey Puck (Subject 17).

The incident occurred during a competitive interscholastic hockey game in which the boy rose from a prone position after a melee in front of the goal, raised his arms above his head, and was struck in the chest at close range by a puck from a forehand shot toward the goal. Panel A shows the boy with his protective chest gear removed. A relatively small mid-precordial contusion ( $3 \mathrm{~cm}$ in diameter) produced by the impact of the puck is present just to the left of the sternum, demarcated by the blue circle; the blue line delineates the inferior margins of the rib cage. Panel B shows the plastic-and-foam chest and shoulder protector in its proper position as worn by the victim (with arms at his sides); here the contusion appears to be covered by the chest protector. In Panel $\mathrm{C}$, the arms of the victim are raised (to simulate their position at the moment of the accident, when the victim was attempting to break the flight of the puck), elevating the chest and shoulder padding and leaving the area of impact unprotected. 


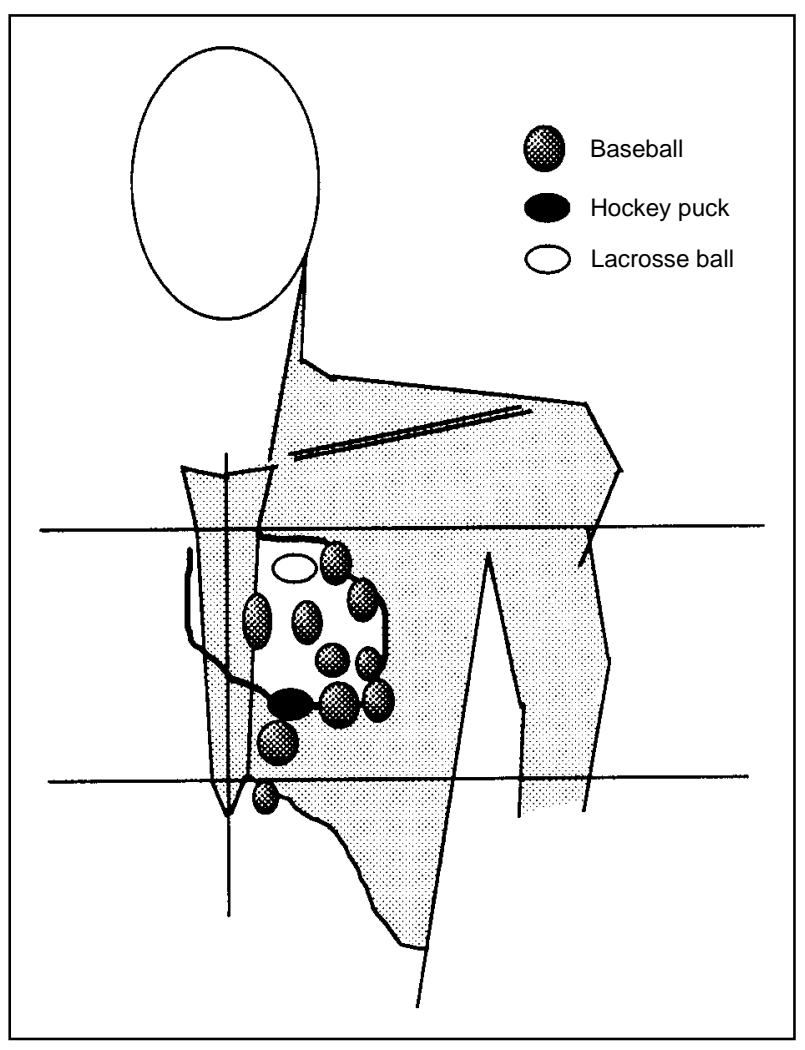

Figure 3. Schematic Representation of the Locations of Impact Points (Contusions) Judged to Have Been Produced by Baseballs $(N=10)$, a Hockey Puck, and a Lacrosse Ball on the Anterior Chest Walls of 12 Victims of Commotio Cordis.

The estimated contour of the heart is indicated by the heavy line.

usually to the left of the sternum and extending laterally to the nipple line (Fig. 3). Therefore, the vast majority of the precordial contusions appeared to be directly over the left ventricle. Other minor bruises, small lacerations, and puncture wounds identified on the chest wall, heart, pericardium, and lungs, as well as one fractured rib, were judged to represent the consequences of resuscitative efforts in 11 victims. Postmortem toxicologic examination of blood or urine was performed in 15 of the 25 subjects and was negative in each case.

\section{Discussion}

This report describes a series of young sports participants in whom sudden, blunt, nonpenetrating impact to the chest was responsible for virtually instantaneous cardiac arrest and death, with no accompanying traumatic injury to either the heart or the great vessels. ${ }^{16-20}$ These catastrophes, previously referred to as cardiac concussion or commotio cordis, ${ }^{16-21}$ are notable because they occurred in structurally normal hearts without injury to the myocardium, cardiac valves, or coronary arteries, ${ }^{22,23}$ in contrast to the circumstances in other athletic-field deaths that are known to be the consequences of structural and usually congenital heart disorders..$^{2-12}$

We found examples of cardiac arrest induced by blunt impact that occurred either during competitive athletic activities or in play. An element common to all of these incidents was a blow to the chest that did not appear to be of sufficient force or magnitude to cause cardiac arrest, so that the dramatic physiologic consequences seemed greatly disproportionate to the apparent trauma.

In the present study group, sudden death after a blunt impact to the chest occurred most often in children participating in competitive youth baseball, an activity in which this issue has perhaps stirred the greatest debate. ${ }^{13-15,17,24-26}$ The most common scenario involved a batter being struck in the mid-chest by a pitched ball, thrown with a velocity judged by witnesses not to be unusual for the game. However, cardiac arrest resulting from blunt impact was not caused only by baseballs; other projectiles, including a hockey puck and a lacrosse ball, delivered at apparently normal velocities, were responsible for similar catastrophes. Therefore, the great majority of deaths encountered in this study involved relatively localized point contact with the middle of the chest. On the other hand, in about 15 percent of the victims, there was more extensive, broad-surface contact with the chest, as a result of bodily collision, tackling, or kicking.

The precise mechanisms of cardiac arrest in commotio cordis have not been determined with certainty. Several theories have been advanced, involving apnea, profound vasovagal reflex, and primary ventricular arrhythmia. ${ }^{14,16}$ The last-mentioned is probably the most credible explanation, because it is consistent with the mechanism demonstrated in animal models, in which ventricular fibrillation was produced by experimentally propelling baseballs at high speed at the animals' chests, ${ }^{24}$ as well as with the clinical profile developed for the majority of victims described in the present study. In most of these events, a focused impact of short duration with virtually no rebound (by a baseball, for example) could be expected to effect a rapid and almost complete transfer of energy to the chest. Such a sudden blow would theoretically be lethal if delivered by chance at an especially vulnerable period of the cardiac cycle (e.g., the upstroke or peak of the $\mathrm{T}$ wave), ${ }^{27,28}$ disrupting the electrical stability of the heart and eliciting repetitive activity. External mechanical cardiac stimulators positioned on the precordium have been shown to be capable of easily and reproducibly inducing ventricular premature beats in both animals and patients with and without heart disease..$^{29,30}$ This suggests that the mechanism for commotio cordis may be precipitation of a premature beat, which in turn elicits ventricular fibrillation.

Sixty percent of the victims appeared to have had virtually instantaneous cardiac arrest at the time of the impact (presumably with ventricular fibrillation), whereas the other 40 percent, after either collapsing immediately on impact or remaining upright briefly, were conscious and active in the ensuing moments (e.g., rising, standing, walking a few steps, or speaking) before finally collapsing once again, this time in cardiac arrest. These descriptions of noninstantaneous death 
suggest that brief periods of primary arrhythmia (such as ventricular tachycardia) occurred initially, followed by rapid deterioration into ventricular fibrillation. In addition, the higher incidence of commotio cordis in young people (70 percent of our patients were $<16$ years of age and none were $\geqslant 20$ ) suggests that children may be more susceptible because of their particular thoracic architecture, possibly by virtue of greater chestwall compliance..$^{16,17}$

These observations raise questions bearing on public safety and health - in particular, whether some form of chest protection would reduce this type of fatal injury in certain organized games (such as for the batter in youth baseball). Certainly, the majority of the victims were not wearing protective padding capable of reducing impact to the critical precordial area. However, it should also be emphasized that 28 percent of the victims (44 percent of the competitive athletes) were in fact wearing some kind of standard padding that theoretically should have reduced the direct impact to the chest; they included a baseball catcher, a lacrosse goalie, a football player, and four hockey players. This observation would suggest that the chest padding worn by these athletes was ineffective in absorbing the energy transfer on impact. For example, one 15-year-old hockey player wore standard shoulder and chest padding that may have become displaced just before contact, leaving his lower chest unprotected. Therefore, before blanket policies are instituted for large populations judged to be at risk, ${ }^{26}$ future efforts at protecting young athletes from the consequences of nonpenetrating blunt impact to the chest should focus on identifying the mechanisms responsible for cardiac arrest in these cases and on the optimal designs for chest protectors and softer-core baseballs. $24,25,31$

Another feature of commotio cordis is the apparently low rate of rescue - that is, the inability of others to resuscitate victims successfully despite reasonably prompt cardiopulmonary resuscitation or electrical cardioversion and the fact that the heart is structurally normal. We could find only one report of the successful resuscitation of a victim after what appeared to be commotio cordis. ${ }^{17}$ Because of the unusual nature of cardiac arrest induced by blunt impact, the possibility may be raised that occult or unrecognized structural cardiovascular disease or drug abuse somehow contributed to these catastrophes. We believe that this is unlikely, since all the victims had been healthy, without a history of heart disease, and all autopsy and toxicologic examinations were normal. On the other hand, since none of the victims had had cardiovascular assessments during life, electrocardiograms were not available to rule out rare congenital conditions undetectable at autopsy, such as the long-QT syndrome. ${ }^{32,33}$ Also, since detailed analysis of the conduction system is not a standard part of the autopsy examination performed by medical examiners, structural abnormalities in this region of the heart could not be definitively ruled out in our study subjects. ${ }^{11,34}$

This study does not address the prevalence of cardiac arrest induced by blunt impact to the chest. Un- avoidable limitations in the identification and selection of cases prohibited the assembly of a consecutive series reflecting the true frequency of these catastrophes. However, we believe that because a comprehensive registry is lacking, injuries of this nature are probably underreported. Nevertheless, blunt impact to the chest leading to sudden death is undoubtedly uncommon, not unlike the sudden catastrophes occurring in young athletes that are due to underlying cardiovascular disease. ${ }^{2-12,35}$ However, the relative rarity of commotio cordis does not reduce its importance and should not prevent its recognition as a true clinical event (rather than as an inexplicable random phenomenon that defies logic). Indeed, cardiac arrest induced by blunt impact has been so poorly understood that athletic-field deaths of this kind have occasionally been regarded as criminal acts rather than as physiologic catastrophes. ${ }^{36}$

We hope that this profile of 25 cases of commotio cordis will provide the basis for a better understanding of this clinical entity and will stimulate efforts to define its mechanism. We hope this information will also aid in the development of measures to prevent a phenomenon that is responsible for the unexpected deaths of healthy young people.

\section{REFERENCES}

1. Maron BJ. Sudden death in young athletes — lessons from the Hank Gathers affair. N Engl J Med 1993;329:55-7.

2. Burke AP, Farb A, Virmani R, Goodin J, Smialek JE. Sports-related and nonsports-related sudden cardiac death in young adults. Am Heart J 1991;121: 568-75.

3. Cheitlin MD, De Castro CM, McAllister HA. Sudden death as a complication of anomalous left coronary origin from the anterior sinus of Valsalva, a not-so-minor congenital anomaly. Circulation 1974;50:780-7.

4. Maron BJ, Roberts WC, McAllister HA, Rosing DR, Epstein SE. Sudden death in young athletes. Circulation 1980;62:218-29.

5. Maron BJ, Epstein SE, Roberts WC. Causes of sudden death in competitive athletes. J Am Coll Cardiol 1986;7:204-14.

6. Thiene G, Pennelli N, Rossi L. Cardiac conduction system abnormalities as a possible cause of sudden death in young athletes. Hum Pathol 1983;14: 704-9.

7. Corrado D, Thiene G, Nava A, Rossi L, Pennelli N. Sudden death in young competitive athletes: clinicopathologic correlations in 22 cases. Am J Med 1990;89:588-96.

8. Maron BJ, Shirani J, Mueller FO, Cantu FC, Roberts WC. Cardiovascular causes of "athletic field" deaths: analysis of sudden death in 84 competitive athletes. Circulation 1993;88:Suppl:I-50. abstract.

9. Tsung SH, Huang TY, Chang HH. Sudden death in young athletes. Arch Pathol Lab Med 1982;106:168-70.

10. Topaz O, Edwards JE. Pathologic features of sudden death in children, adolescents, and young adults. Chest 1985;87:476-82.

11. James TN, Froggatt P, Marshall TK. Sudden death in young athletes. Ann Intern Med 1967;67:1013-21.

12. Furlanello F, Bettini R, Cozzi F, et al. Ventricular arrhythmias and sudden death in athletes. Ann N Y Acad Sci 1984;427:253-79.

13. Rutherford GW, Miles RB, Brown VR, MacDonald B. Overview of sportsrelated injuries to persons 5-14 years of age. Washington, D.C.: Consumer Product Safety Commission, December 1981.

14. Viano DC, Andrzejak DV, King AI. Fatal chest injury by baseball impact in children. Clin J Sport Med 1992;2:161-5.

15. King AI, Viano DC. Baseball related chest impact. Final report to Consumer Product Safety Commission. Washington, D.C.: Consumer Product Safety Commission, July 15, 1986. (\#CPSC-C-84-1170.)

16. Kaplan JA, Karofsky PS, Volturo GA. Commotio cordis in two amateur ice hockey players despite the use of commercial chest protectors: case reports. J Trauma 1993;34:151-3.

17. Abrunzo TJ. Commotio cordis: the single, most common cause of traumatic death in youth baseball. Am J Dis Child 1991;145:1279-82.

18. Edlich RF Jr, Mayer NE, Fariss BL, et al. Commotio cordis in a lacrosse goalie. J Emerg Med 1987;5:181-4.

19. Frazer M, Mirchandani H. Commotio cordis, revisited. Am J Forensic Med Pathol 1984;5:249-51. 
20. Green ED, Simson LR Jr, Kellerman HH, Horowitz RN, Sturner WQ. Cardiac concussion following softball blow to the chest. Ann Emerg Med 1980; 9:155-7.

21. Külbs F. Experimentelle Untersuchungen über Herz und Trauma. Mitt Grenzgeb Med Chir 1909;19:678-702.

22. Pringle SD, Davidson KG. Myocardial infarction caused by coronary artery damage from blunt chest injury. Br Heart J 1987;57:375-6.

23. Grossfeld PD, Friedman DB, Levine BD. Traumatic myocardial infarction during competitive volleyball: a case report. Med Sci Sports Exerc 1993;25:901-3.

24. Viano DC, Andrzejak DV, Polley TZ, King AI. Mechanism of fatal chest injury by baseball impact: development of an experimental model. Clin J Sport Med 1992;2:166-71.

25. Janda DH, Viano DC, Andrzejak DV, Hensinger RN. An analysis of preventive methods for baseball-induced chest impact injuries. Clin J Sport Med 1992;2:172-9.

26. Ferstle J. Baseball deaths: unrecorded, preventable. Physician Sportsmed 1978;6(a):21-2.

27. Smirk FH, Palmer DG. A myocardial syndrome: with particular reference to the occurrence of sudden death and of premature systoles interrupting antecedent T waves. Am J Cardiol 1960;6:620-9.
28. Lown B, Klein MD, Hershberg PI. Coronary and precoronary care. Am J Med 1969;46:705-24.

29. Cohn PF, Angoff GH, Zoll PM, et al. A new, noninvasive technique for inducing post-extrasystolic potentiation during echocardiography. Circulation 1977;56:598-605

30. Zoll PM, Belgard AH, Weintraub MJ, Frank HA. External mechanical cardiac stimulation. N Engl J Med 1976;294:1274-5.

31. Cooper GJ, Taylor DE. Biophysics of impact injury to the chest and abdomen. J R Army Med Corps 1989;135:58-67.

32. Moss AJ, Schwartz PJ, Crampton RS, Locati E, Carleen E. The long QT syndrome: a prospective international study. Circulation 1985;71:17-21.

33. Vincent GM, Timothy KW, Leppert M, Keating M. The spectrum of symptoms and QT intervals in carriers of the gene for the long-QT syndrome. N Engl J Med 1992;327:846-52.

34. Viano DC, Artinian CG. Myocardial conducting system dysfunctions from thoracic impact. J Trauma 1978;18:452-9.

35. Ragosta M, Crabtree J, Sturner WQ, Thompson PD. Death during recreational exercise in the State of Rhode Island. Med Sci Sports Exerc 1984;16: 339-42.

36. Swift EM. A cruel blow. Sports Illustrated. December 6, 1993:66-79.

Because the great majority of television and radio news programs now begin at 5 p.m. Eastern time, the Journals embargo time for these media has been changed from 6 to 5 p.m. Wednesday, beginning with the July 6 issue. The embargo time for the print media will continue to be Thursday morning, the day of publication. 